\title{
Patient adherence and the choice of antihypertensive drugs: focus on lercanidipine
}

\author{
Menno T Pruijm \\ Marc P Maillard \\ Michel Burnier \\ Service of Nephrology \\ and Hypertension, Department \\ of Medicine, University Hospital, \\ Lausanne, Switzerland
}

Correspondence: Michel Burnier Service de Néphrologie et Hypertension, CHUV, Rue du Bugnon 17, 1005 Lausanne, Switzerland

Email michel.burnier@chuv.ch

\begin{abstract}
Despite the development of many effective antihypertensive drugs, target blood pressures are reached in only a minority of patients in clinical practice. Poor adherence to drug therapy and the occurrence of side effects are among the main reasons commonly reported by patients and physicians to explain the poor results of actual antihypertensive therapies. The development of new effective antihypertensive agents with an improved tolerability profile might help to partly overcome these problems. Lercanidipine is an effective dihydropyridine calcium channel blocker of the third generation characterized by a long half-life and its lipophylicity. In contrast to first-generation dihydropyridines, lercanidipine does not induce reflex tachycardia and induces peripheral edema with a lower incidence. Recent data suggest that in addition to lowering blood pressure, lercanidipine might have some renal protective properties. In this review we shall discuss the problems of drug adherence in the management of hypertension with a special emphasis on lercanidipine.
\end{abstract}

Keywords: compliance, hypertension, calcium antagonists

\section{Introduction}

Hypertension is one of the biggest health care problems of Western populations, as it is the major risk factor for strokes, acute coronary events and chronic kidney disease (Collins and Peto 1994). Its prevalence is high and its incidence continues to rise around the world. For example, data form the latest National Health Nutrition Examination Survey (NHANES), conducted between 1999 and 2000, have shown a prevalence of $28.7 \%$ in American adults, compared with $25 \%$ in a similar survey conducted between 1988 and 1991 (Hajjar et al 2003). In Switzerland, data from a recent stroke prevention campaign, which included 4458 persons (age $57.8 \pm 15$ years) visiting local shopping malls in 2001, showed a prevalence of hypertension of $47 \%$ (Nedeltchev et al 2005).

Research efforts have resulted in the development of many effective antihypertensive drugs. Clinical trials using these agents have lead to well defined indications and treatment goals, in order to prevent irreversible organ damage due to hypertension. In recent years, an increasing number of patients are being treated with antihypertensives, although the percentage of treated hypertensive patients remains largely insufficient and is estimated at only 30\% to 45\% (MMWR 2005).

The most important aspect of pharmacological treatment of hypertension is to obtain a sustained normalization of blood pressure, irrespective of the drug class used. Since hypertension is a chronic, usually asymptomatic, disorder needing life-long treatment, thorough adherence to medication is important. Unfortunately, non-compliance is a frequent issue, its prevalence varying from $17 \%$ to $60 \%$ depending on the definition used and the methods applied to detect non-compliance (Joint National Committee 1997; Caro et al 1999; Nuesch et al 2001). The economic burden of non-adherence is important, not to mention the clinical consequences for patients. 
Several factors play a role in medication adherence, but amongst the key determinants are the complexity of the medication regimen and the side effect profile of the drug used. In this review, the problems of adherence in treating hypertension and their relationship with the side effect profile of several drug classes will be discussed with a special emphasis on the third-generation calcium antagonist lercanidipine.

\section{Drug adherence and the treatment of hypertension Definitions and detection}

Many different definitions of compliance are used in the literature, which makes comparison of studies sometimes difficult. Besides, some argue that "compliance" has nowadays a somewhat negative connotation, merely implying "obedience to physicians orders". Therefore, some authors have proposed using the term adherence rather than compliance (Loghman-Adham 2003). Medication adherence can be defined as "the extent to which a patient's behavior, with respect to taking medication, corresponds with agreed recommendations from healthcare providers" (WHO 2003). Adherence can be divided into two main components: persistence and execution. Persistence is defined as the time from the first to the last dose taken, eg, the time during which the drug has been taken, whereas the execution refers to the comparison between the prescribed drug dosing regimen and the patient's drug history while on treatment. The latter definition includes dose omissions (missed doses) and the so-called "drug holidays" (3 or more days without drug intake) (Urquhart et al 2005). While non-persistence can be identified, for example, by the failure of patients to collect a second prescription in a pharmacy registry, it is very difficult to diagnose poor execution with traditional methods such as patient diaries and measurements of plasma drug concentrations, which in general tend to overestimate adherence (Pullar et al 1989; Waeber et al 1999). More insights into specific drug intake patterns of antihypertensives have been gained by using electronic pill box monitoring (Medical Event Monitoring System, MEMS ${ }^{\circledR}$ ), which enables monitoring of the execution on a daily basis by recording the time of each opening of the pill container (Kruse and Weber 1990). Several lessons have been learned from this device. First, adherence is a dynamic process that fluctuates in time, meaning that phases of good adherence can alternate with phases of poor compliance in the same patient. For example, patients tend to be more compliant around the time of a follow-up visit; this has led to the term "white coat compliance". Second, persistence decreases progressively over time, the largest decrease occurring during the first 6 to 8 months of therapy (Burnier et al 2003). Third, patients who have poor execution (omitting doses, drug holidays, variability in hour of intake) are at highest risk of quitting early, thus leading to poor persistence. Fourth, "morning takers" are more likely to have a good execution than "evening takers" (Vrijens et al 2008).

These findings have led Vrijens et al to propose some practical recommendations: whenever possible, drugs should be taken in the morning and one should try to prescribe drugs that sustain full pharmacological action for one or two dosing cycles after omitted doses.

\section{Adherence according to antihypertensive drug classes}

Several studies have compared medication adherence of different drug classes. The largest trials are outlined in Table 1. Most of these data are derived from prescription databases that give insight into persistence but not in execution. Despite differences in design, these studies show the same tendency, namely that angiotensin (AT)-II blockers and angiotensin converting enzyme (ACE)-inhibitors have a slightly higher persistence than, respectively, calcium antagonists and beta blockers, and that persistence with diuretics is the lowest.

Table I Studies comparing adherence rates of different antihypertensive drugs

\begin{tabular}{llllllll}
\hline Study & $\mathbf{n}$ & Outcome (persistence) & AT-II blockers & ACE-inhibitors & $\begin{array}{l}\text { Calcium } \\
\text { antagonists }\end{array}$ & Beta-blockers & Diuretics \\
\hline Blooms 1998 & 21,723 & I-year persistence & $64 \%$ & $58 \%$ & $50 \%$ & $43 \%$ & $38 \%$ \\
Caro 1999 & 22,918 & 4.5 -year persistence & $n e^{\mathrm{b}}$ & $53 \%$ & $47 \%$ & $49 \%$ & $40 \%$ \\
Morgan 2004 & 82,824 & I-year persistence & $56 \%$ & $56 \%$ & $52 \%$ & $54 \%$ & $49 \%$ \\
Polluzzi 2005 & 6,043 & 3-year persistence* & $52 \%$ & $43 \%$ & $39 \%$ & $47 \%$ & $23 \%$ \\
Simons 2008 & 48,690 & 33-month persistence & $84 \%$ & $84 \%$ & $72 \%$ & ne & ne \\
\hline
\end{tabular}

${ }^{\mathrm{a} A l l}$ theses studies are retrospective.

bnot evaluated. 
This drug class difference in treatment persistence has raised some questions. Confounding factors could have influenced the results. However, correction for several factors including age, gender, number of physician visits or hospital admissions did not change the results. According to a questionnaire-based survey among primary care physicians in Italy, the main reasons for drug discontinuation are treatment failure and side effects (Ambrosioni et al 2000). A similar observation was made in Switzerland where lack of efficacy and the side effect profile were identified as the main determinants of non-persistence (Burnier et al 2005). Large prospective clinical trials have also shown differences in discontinuation rates in favor of ACE-inhibitors and AT-II blockers. On average, drug interruptions occur in $15 \%$ of patients taking ACE-inhibitors and in $20 \%$ of patients taking beta blockers, diuretics or calcium antagonists; among the main reasons for drug interruption were once again side effects (Shulman et al 1982; Croog et al 1986; Jones et al 1995). These trials, however, were not designed to compare persistence rates but compared clinical endpoints such as stroke and other cardiovascular events.

Finally, one Italian prospective study examining persistence of antihypertensive treatment in 347 patients confirms the findings of Table 1 . In this study, mild to moderate hypertensive patients were randomly allocated to monotherapy with either ACE-inhibitors, AT-II blockers, calcium antagonists, beta blockers or diuretics, and followed for 24 months (Veronesi et al 2007). Persistence of treatment was highest among ACE-inhibitors (64.5\%) and ATII-blockers (68.5\%), as compared to calcium-antagonists $(51.6 \%)$, beta blockers (44.8\%) and diuretics (34.4\%). The main reason for drug interruption was the occurrence of side effects. Age $>65$ years (odds ratio [OR]: 1.27) and female sex (OR 1.08) were associated with higher persistence. ACE-inhibitors and AT-II inhibitors are well known for their favorable side effect profile, and a further discussion of these drug categories is beyond the scope of this article. Calcium antagonists show slightly lower persistence rates (Table 1). Interestingly, in the study by Veronesi et al patients treated with lercanidipine were more likely to persist than patients taking other dihydropyridines (59.3\% vs $46.6 \%$; OR: 1.43 ), which brings us to discuss this compound more in detail.

\section{Lercanidipine, a well tolerated calcium channel blocker}

Calcium antagonists represent a heterogeneous group of agents, including mainly the dihydropyridines (DHP), verapamil and diltiazem. Lercanidipine is a third-generation calcium antagonist with an improved side effect profile, which makes it - in terms of adherence - an interesting compound, alone or in combination with other antihypertensives in the treatment of hypertension.

\section{Pharmacology}

Lercanidipine is a member of the 1,4-DHP calcium channel blocker class which blocks the influx of calcium via competitive antagonism of L-type calcium channels, thus leading to smooth muscle relaxation and vasodilatation (Herbette et al 1997). Lercanidipine is almost completely absorbed from the gastrointestinal tract and reaches its maximal plasma concentration after 1 to 3 hours. It is highly bound to proteins (>98\%) and has a distribution volume of 2 to $2.5 \mathrm{~L} / \mathrm{kg}$ (Bang et al 2003). Lercanidipine is highly lipophylic: hence the drug has a better penetration in hydrophobic cell membranes than other DHPs and penetrates even in smooth muscle cells surrounded by cholesterol-rich plaques (Herbette et al 1997). This might explain its high efficiency in a wide range of patients, including patients with a high cardiovascular risk profile and diffuse atherosclerosis.

Another property of lercanidipine is a long duration of action, resulting in 24-hour blood pressure control after a single dose (Beckey et al 2007) despite a short plasma half-life. Once again, its lipophylic profile explains this apparent discrepancy, as lercanidipine is quickly stored in the hydrophobic component of the cell membrane layer. Lercanidipine induces a slow-onset, prolonged smooth muscle relaxation, resulting in peripheral and coronary vasodilatation and thus steady lowering of the blood pressure without important reflex tachycardia (Sironi et al 1996). Lercanidipine is metabolized by CYP3A4; plasma concentrations are thus influenced by inducers or inhibitors of $3 \mathrm{~A} 4$ such as cimetidine, ketoconazole and grapefruit juice.

\section{Tolerability profile of lercanidipine}

In contrast to beta blockers and diuretics, which may worsen insulin resistance (Mason et al 2005) and increase total cholesterol, low density lipoprotein and total glyceride levels (Weir and Moser 2000) and hence the risk of diabetes (Gress et al 2000), calcium antagonists are metabolically neutral. In the ASCOT trial, for example, the combination of atenolol/ flumethazine was associated with a significantly higher risk of new onset diabetes compared with the group treated with perindopril and amlodipine (Dahlöf et al 2005), especially when fasting plasma glucose was $>5 \mathrm{mmol} / \mathrm{L}$ (Gupta et al 2008). The widespread use of calcium antagonists in clinical practice has been limited, however, by one frequent side 
effect - peripheral edema. Thus, in ASCOT, for example, peripheral edema developed in $23 \%$ of treated patients, and was the leading cause of interruption of amlodipine.

The main advantage of lercanidipine is that it induces less peripheral edema than other DHPs. On average, peripheral edema develops in $0.6 \%$ to $9 \%$ of treated patients (at the dose of $10 \mathrm{mg}$ daily), which is considerably lower than the $23 \%$ reported in the ASCOT trial (Table 2). Observational studies have shown that in patients previously treated with another DHP, switching from a first-generation DHP to lercanidipine reduces the likelihood of developing peripheral edema by approximately 50\% (Borghi et al 2003). In an observational study of Burnier et al (2007), this likelihood was even lower. This observational, prospective, phase IV study investigated the efficacy and tolerability of lercanidipine as prescribed in private practices in Switzerland. Lercanidipine was prescribed as monotherapy ( $n=683)$, or as step-on therapy $(n=844)$, or as substitution for another drug $(\mathrm{n}=672)$ to hypertensive patients (mean age 58-69 years; 10\%-22\% diabetics); doses were uptitrated to $20 \mathrm{mg}$ in case of insufficient blood pressure control after 4 weeks. Of the 182 patients that started lercanidipine because of peripheral edema with another calcium antagonist, only 10 experienced edema on lercanidipine. Moreover, the persistence was very high at $98 \%-99 \%$ and $63 \%$ reached the target blood pressure ( $\leq 140 / 90 \mathrm{mmHg}$ ) (Burnier et al 2007). An even larger study including 9059 Spanish patients (ELYPSE study, Table 2), found similar results: the overall incidence of adverse events was $6.5 \%$, of which $2.9 \%$ was headache, $11 \%$ flushing, $0.6 \%$ palpitations and only $1.2 \%$ ankle edema (Barrios et al 2002). Persistence was $>99 \%$, although the follow-up period was, again, rather short.

The highest rate of peripheral edema (39.7\%) was found in the TOLERANCE study (Barrios et al 2008). This observational study included 650 hypertensive patients on lercanidipine or another DHP (amlodipine or nifedipine GITS) who were uptitrated from a low dose ( $10 \mathrm{mg}, 5 \mathrm{mg}$ and $30 \mathrm{mg}$ respectively) to a high dose (20 $\mathrm{mg}, 10 \mathrm{mg}$ and $60 \mathrm{mg}$ ) of the mentioned drugs. Two explanations might explain the high rate of peripheral edema in this study. Firstly, the peripheral edema was reported by the patient and might have been overestimated. Secondly, the dose of lercanidipine used was higher than in the other studies. Finally, the peripheral edema did not lead to drug interruption, as illustrated by high adherence rates (93.9 vs 93.7\% in the amlodipine/nifedipine group).

All these studies were observational, non-randomized studies, and thus selection bias cannot be excluded and the findings should be interpreted with caution. However, the only prospective, double-blind randomized trial-performed in stage I or II hypertensive elderly patients ( $\geq 60$ years) also found significantly more edema in the amlodipine group than in the lercanidipine or lacidipine group (COHORT) (Degiorgio et al 1999).

Why lercanidpine leads to less leg edema remains unknown. It is generally believed that DHPs induce an increase in the intra-capillary hydrostatic pressure due to arteriolar vasodilatation, and that reflex sympathetic activation avoids adequate post-capillary venous vasodilatation (Angelico et al 1999). Lercanidipine induces less sympathetic activation and thus less peripheral edema than other DHPs (Fogari et al 2003). Although a single-blind cross-over study in 22 male hypertensive patients confirmed the difference in edema-forming potential as measured by the water displacement method, this study did not find a difference in interference with postural vasoconstrictor mechanisms between amlodipine (10 $\mathrm{mg})$ and lercanidipine (20 mg) (Pedrinelli et al 2003).

Thanks to its slow onset of action, reflex tachycardia is rare, as well as flushing and acute hypotension. This was illustrated by an analysis of 14 placebo-controlled,

Table 2 Large trials having evalauted the tolerability and efficacy of lercanidipine therapy in daily clinical practice

\begin{tabular}{|c|c|c|c|c|c|}
\hline Study (year) ${ }^{a}$ & $\mathbf{n}$ & Type & Medication & Duration & Peripheral edema (\%) \\
\hline $\begin{array}{l}\text { LAURA study } \\
2006\end{array}$ & 3175 & $\begin{array}{l}\text { Open label, } \\
\text { non-comparative }\end{array}$ & Lercanidipine $10-20 \mathrm{mg} /$ day & 6 months & 5.1 \\
\hline $\begin{array}{l}\text { TOLERANCE } \\
\text { study } 2008\end{array}$ & 650 & Observational & $\begin{array}{l}\text { Lercanidipine } 20 \mathrm{mg} \text { vs amlodipine } \\
10 \mathrm{mg} \text { or nifedipine GITS } 60 \mathrm{mg}\end{array}$ & 2 months & 39.7 vs 57.3 \\
\hline Burnier 2007 & 2199 & $\begin{array}{l}\text { Observational, } \\
\text { non-interventional }\end{array}$ & $\begin{array}{l}\text { Lercanidipine } 10 \mathrm{mg} / 20 \mathrm{mg} \text {; mono, } \\
\text { step on, or substitution therapy }\end{array}$ & 2 months & $0.6-3$ \\
\hline ELYPSE 2002 & 9059 & Observational & Lercanidipine $10 \mathrm{mg}$ & 3 months & 1.2 \\
\hline $\begin{array}{l}\text { COHORT } \\
2002\end{array}$ & 828 & $\begin{array}{l}\text { Prospective, randomized, } \\
\text { double blind }\end{array}$ & $\begin{array}{l}\text { Lercanidipine } 10 \mathrm{mg} \text { vs amlodipine } \\
5 \mathrm{mg} \text { vs lacidipine } 2 \mathrm{mg}\end{array}$ & 12 months & 9 vs 19 vs 4 \\
\hline
\end{tabular}

aStudies were selected by performing a Pubmed query with "lercanidipine", “adherence", “compliance” and "tolerability” as search terms. 
double-blind trials including 1850 patients: $2.1 \%$ of patients presented tachycardia, $1.7 \%$ palpitations and $2.0 \%$ flushing (Hollenberg 2002). Its vasodilatatory properties and its lack of sympathetic activation probably explain its anti-anginal actions (Sasaki et al 2005). This anti-ischemic effect was evaluated in a study including 23 patients with stable angina who performed bicycle exercise testing and simultaneous ambulatory radionuclide testing to estimate the left ventricular function, before and after the introduction of lercanidipine $10 \mathrm{mg}$ to $20 \mathrm{mg}$. Lercanidipine increased in a dose-dependent way the time to onset of ST depression and improved total exercise duration, without changing heart rate with respect to pretreatment level (Acanfora et al 2004).

\section{Clinical efficacy of lercanidipine}

Several studies have demonstrated the efficacy of lercanidipine monotherapy in the treatment of hypertension. Reductions of systolic and diastolic blood pressure of respectively 19 to $26 \mathrm{mmHg}$ and 13 to $15 \mathrm{mmHg}$ have been reported with lercanidipine, and non-inferiority studies have shown that lercanidipine is as effective in lowering blood pressure as, for example, atenolol, hydrochlorothiazide, captopril, telmisartan and amlodipine. Calcium antagonists are particularly suitable for patients with the Raynaud phenomenon or angina pectoris and they are effective in stroke prevention (Basile 2004; Verdecchia et al 2005). For a detailed review of these studies, we refer the reader to the excellent article that has been published previously in this journal (Borghi 2005). Since then, clinical studies have been performed to investigate the role of lercanidipine in combination therapy and its potential renal protective properties.

\section{Use of lercanidipine in combination therapies}

The majority of hypertensive patients need at least two or three drugs to control their blood pressure, and lifelong treatment is necessary to prevent organ damage (Mancia et al 2007). Calcium antagonists are interesting drugs for combination therapy because of their mentioned favorable side effect profile and metabolic neutrality. They are effective when used in combination with ACE-inhibitors, AT-II blockers, thiazide diuretics and beta blockers (Mancia et al 2007) and since the results of the ASCOT trial combinations of calcium channel blockers and blockers of the renin-angiotensin system have become increasingly popular. Lercanidipine has received special interest thanks to its mild side effect profile, and the performed combination therapy studies are mentioned in Table 3. As can be seen, these studies had

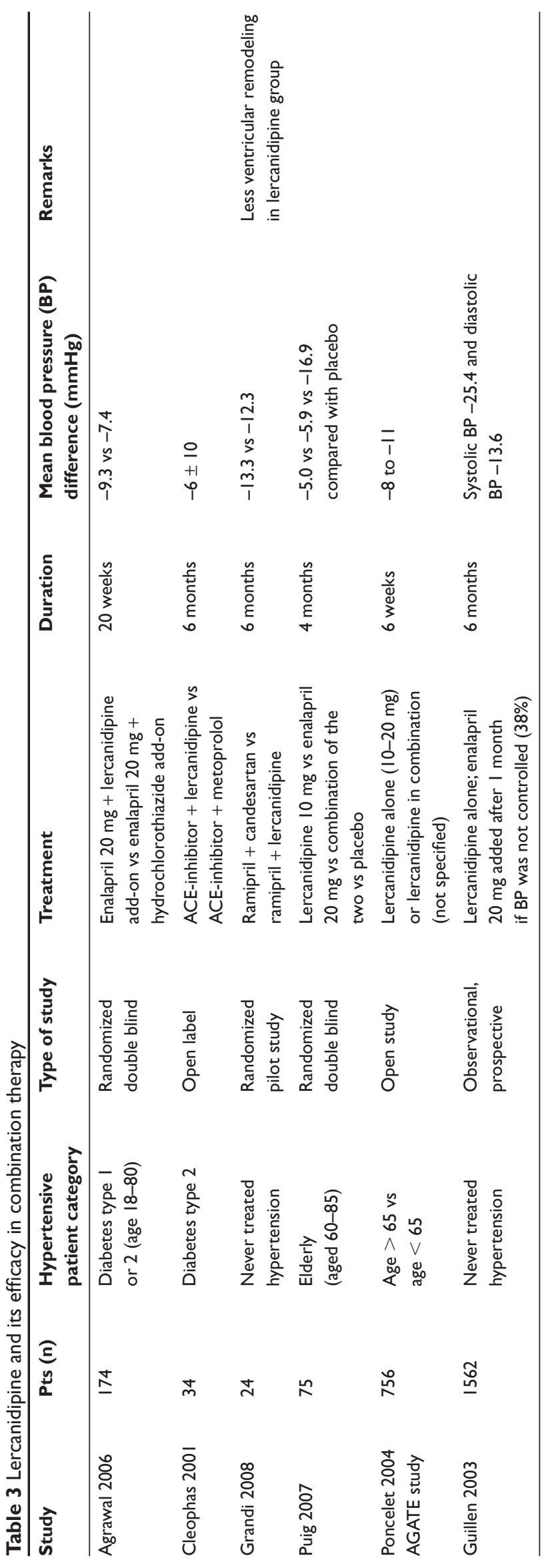


a rather short follow-up period, enrolled a relatively small number of patients and were often not blinded. Thus, more studies are needed to determine the place of lercanidipine in the combination therapy of hypertension.

\section{Lercanidipine in renal protection}

Studies examining the role of calcium antagonists for renal protection and to reduce proteinuria have provided conflicting results. Some studies, such as the SYST-EUR trial and the ALLHAT study, showed results in favor of, respectively, nitrendipine and amlodipine compared with placebo (SYST-EUR) or diuretics (ALLHAT) (Voyaki et al 2001; the ALLHAT officers 2002). However, other studies, such as the African American Study of Kidney Disease (AASK), were discouraging. In this study, amlodipine significantly increased proteinuria compared with metoprolol or ramipril (Douglas and Agodoa 2003).

These conflicting results may partly be explained by the heterogeneity of calcium antagonists as a group and particularly their different impact on renal hemodynamics. Non-DHPs as well as DHPs mainly dilate the afferent preglomerular arterioles, thus resulting in relatively unchanged or increased renal plasma flow (RPF) but higher glomerular filtration rate (GFR) which might result in raised intra-glomerular capillary pressure (Arima et al 1996). However, a growing body of evidence suggests that some DHPs also vasodilate the efferent, post-glomerular vessels and thus lower intra-glomerular pressure. This has been reported, for example, when manidipine, a third-generation calcium antagonist, was administered to spontaneous hypertensive rats (SHR). Upon administration of manidipine, RPF increased more than GFR, resulting in decreased filtration fraction (Takabatake et al 1993). Lercanidipine also possesses post-glomerular vasodilatory capacities. This was shown by Sabbatini et al (2000), who treated SHR for 12 weeks with lercanidipine and found dilatation of efferent as well as afferent arterioles.

Few clinical studies have examined the role of lercanidipine in patients with chronic kidney damage and/or proteinuria. The ZAFRA study (Zanidip en Función Renal Alterada) is the largest study so far that has addressed this subject (Robles et al 2005). This open label study included 203 patients $(20 \%$ diabetics) with a creatinine clearance below $70 \mathrm{~mL} / \mathrm{min}$ and a higher-than-recommended blood pressure, despite therapy with ACE-inhibitors (63.4\%) or AT-II blockers (36.6\%). Lercanidipine $10 \mathrm{mg}$ was added and patients were followed for 6 months. Systolic blood pressure decreased from $162 \pm 16.6$ to $131.6 \pm 11.6 \mathrm{mmHg}$, diastolic blood pressure decreased from $93.2 \pm 8.3$ to $78.2 \pm 6.4 \mathrm{mmHg}$, creatinine clearance improved from $41.8 \pm 16.0$ to $45.8 \pm 18.0 \mathrm{~mL} / \mathrm{min}$ and proteinuria (as measured by 24-hour urine collection) decreased from $3.5 \pm 3.2$ to $2.8 \pm 2.8 \mathrm{~g}$ /day. No patient developed peripheral edema and only one progressed to end stage renal failure. This open label study underlined the safety and antihypertensive potential of lercanidipine in patients with chronic renal failure (CRF). However, the study was not designed to demonstrate eventual blood pressure- independent renoprotective properties of lercanidipine, and further studies are needed to determine its role and properties in CRF patients. In the meantime, a fixed-dose formulation of lercanidipine $10 \mathrm{mg} /$ enalapril $10 \mathrm{mg}$ is approved in Germany for the treatment of hypertension. A 12-week, randomized, double-blind trial showed effective blood pressure lowering and high tolerability of this combination, with $<1.5 \%$ of patients developing peripheral edema (Hair et al 2007).

\section{Conclusions}

Hypertension is an asymptomatic disease needing lifelong lifestyle modifications and drug therapy. Excellent adherence to drug therapy is necessary to achieve strict blood pressure control. The use of antihypertensive agents with a high efficacy in a broad range of patient categories and a favorable tolerability profile is important to improve adherence. Lercanidipine is a third-generation calcium antagonist with a proven antihypertensive efficacy in monotherapy and combination therapy, although many studies were non-randomized, open label trials. Its main advantage over first- and second-generation DHPs is its lower incidence of adverse effects, in particular peripheral edema. Future clinical experience trials will demonstrate whether lercanidipine has indeed renoprotective properties, as suggested by animal studies and small clinical trials. Presently, the development of drugs such as lercanidipine could represent an important step to enhance persistence to therapy in hypertension.

\section{Disclosures}

The authors have no conflicts of interest to disclose.

\section{References}

Acanfora D, Gheorghiade M, Trojano L, et al. 2004. A randomized, double-blind comparison of lercanidipine 10 and $20 \mathrm{mg}$ in patients with stable effort angina: clinical evaluation of cardiac function by ambulatory ventricular scintigraphic monitoring. Am J Ther, 11:423-32.

Agrawal R, Marx A, Haller H. 2006. Efficacy and safety of lercanidipine versus hydrochlorothiazide as add-on to enalapril in diabetic populations with uncontrolled hypertension. J Hypertens, 24:185-92. 
Ambrosioni E, Leonetti G, Pessina A, Rappelli A, Trimarco B, et al. 2000. Patterns of hypertension management in Italy: results of a pharmacoepidemiological survey on antihypertensive therapy. J Hypertens, 18:1691-9.

Angelico P, Guarnieri N, Leonardi A, et al. 1999. Vascular-selective effect of leranidipine and other 1,4 dihydropyridines in isolated rabbit tissues. $J$ Pharm Pharmacol, 51:709-14.

Arima S, Ito S, Omata K, et al. 1996. Role of actions of calcium antagonists on efferent arterioles with special references to glomerular hypertension. Am J Nephrol, 23:229-44.

Bang LM, Chapman TM, Goa KL. 2003. Lercanidipine: a review of its efficacy in the management of hypertension. Drugs, 63:2449-72.

Barrios V, Escobar C, de la Figuera M, et al. 2008. Tolerability of high doses of lercanidipine versus high doses of other dihydropyridines in daily clinical practice: the TOLERANCE study. Cardiovasc Ther, 26:2-9.

Barrios V, Navarro A, Esteras A, et al. 2002. Antihypertensive efficacy and tolerability of lercanidipine in daily clinical practice. The ELYPSE study. Eficacia de Lercanidipino y su Perfil de Seguridad. Blood Press, 11:95-100.

Basile J. 2004. The role of existing and newer calcium channel blockers in the treatment of hypertension. J Clin Hypertens, 6:621-9.

Bloom BS. 1998. Continuation of initial antihypertensive medication after 1 year of therapy. Clin Ther, 20:671-81.

Borghi C. 2005. Lercanidipine in hypertension. Vasc Health Risk Manag, 1:173-82.

Borghi C, Prandin MG, Dormi A, Ambrosioni E: Study group of the regional Unit of the Italian Society of Hypertension. 2003. Improved Tolerability of the dihydropyridine calcium-channel antagonist lercanidipine: the lercanidipine challenge trial. Blood Press Suppl, 1:14-21.

Burnier M, Gasser UE. 2007. Efficacy and tolerability of lercanidipine in patients with hypertension: results of a Phase IV study in general practice. Expert Opin Pharmacother, 8:2215-23.

Burnier M, Santschi V, Favrat B, Brunner HR. 2003. Monitoring compliance in resistant hypertension: an important step in patient management. J Hypertens, 21:S37-42.

Burnier M, Hess B, Greminger P, Waeber B. 2005. Determinants of persistence in hypertensive patients treated with Irbesartan: results of a postmarketing survey. BMC Cardiovasc Disords, 5:13.

Fogari R, Mugellini A, Zoppi A, et al. 2003. Differential effects of lercanidipine and nifedipine GITS on plasma norepinephrine in chronic treatment of hypertension. Am J Hypertens, 16:1357-69.

Caro JJ, Speckman JL, Salas M, et al. 1999. Effect of initial drug choice on persistence with antihypertensive therapy: the importance of actual practice data. CMAJ, 160:41-6.

Cleophas TJ, van Ouwekerk BM, van der Meulen J, et al. 2001. Diabetics with hypertension not controlled with ACE-inhibitors: alternate therapies. Angiology, 52:469-75.

Collins OR, Peto R. 1994. Antihypertensive drug therapy: effects on stroke and coronary heart disease. In: Swales JD, (ed). Textbook of Hypertension. Oxford, England: Blackwell Scientific Publications. p. 1156-64.

Croog SH, Levine S, Testa MA, et al. 1986. The effects of antihypertensive therapy on the quality of life. $N$ Engl J Med, 314:1657-64.

Dahlöf B, Severs PS, Poulter NR, et al. 2005. Prevention of cardiovascular events with an antihypertensive regimen of amlodipine adding perindopril as required versus atenolol adding bendroflumethiazide, in the Anglo-Scandinavian Cardiac Outcomes Trial-Blood Pressure Lowering arm (ASCOT-BPLA): a multicentre randomized controlled trial. Lancet, 366:895-906.

DeGiorgio LA, Orlandini F, Malasoma P, Zappa A. 1999. Double blind, cross-over study of lercanidipine versus amlodipine in the treatment of mild to moderate essential hypertension. Curr Ther Res, 60:511-20.

Douglas JG, Agodoa L. 2003. ACE-inhibition is effective and renoprotective in hypertensive nephrosclerosis: the African American Study of Kidney Disease and Hypertension (AASK) trial. Kidney Int Suppl, 83:S74-6.
Grandi AM, Solbiati F, Laurita E, et al. 2008. Effects of dual blockade of renin-angiotensin system on concentric left ventricular hypertrophy in essential hypertension: a randomized, controlled pilot study. Am J Hypertens, 21:231-7.

Gress TW, Nieto FJ, Shahar E, et al. 2000. Hypertension and antihypertensive therapy as risk factors for type 2 diabetes mellitus. Atherosclerosis risk in communities study. $N$ Engl J Med, 13:905-12.

Guillen VG, Abellan J, Llisterri JL, et al. 2003. Efficacy and safety of lercanidipine in combination with enalapril in HBP. Preliminary results of ZANYCONTROL study group. Am J Hypertens, 16:115A.

Gupta AK, Dahlöf B, Dobson J, et al. 2008. Determinants of new-onset diabetes among 189,257 hypertensive patients randomized in the Anglo-Scandinavian Cardiac Outcomes Trial-Blood Pressure Lowering Arm and the relative influence of antihypertensive medication. Diabetes Care, 31:982-8.

Hair PI, Scott LJ, Perry CM. 2007. Fixed-dose combination lercanidipine/ enalapril. Drugs, 67:95-106.

Hajjar I, Kotchen TA. 2003. Trends in prevalence, awareness, treatment, and control of hypertension in the United States, 1988-2000. JAMA, 290:199-206.

Herbette LG, Vecchiarelli M, Sartani A, Leonardi A. 1998. Lercanidipine: short plasma half-life, long duration of action and high cholesterol tolerance. Updated molecular models to rationalize its pharmacokinetic properties. Blood Press Suppl, 2:10-7.

Hollenberg NK. 2002. Observations on the safety of lercanidipine: adverse events from placebo-controlled trials. Am J Hypertens, 15:58A-59A.

Joint National Committee on Prevention, Detection, Evaluation and Treatment of High Blood Pressure and the National High Blood Pressure Education Program Coordination Committee. The Sixth Report of the Joint National Committee on Prevention, Detection, Evaluation and Treatment of High Blood Pressure. 1997. Arch Intern Med, 157:2413-46.

Jones JK, Gorkin L, Lian JF, et al. 1995. Discontinuation of and changes in treatment after start of new courses of antihypertensiv drugs: a study of a United Kingdom population. BMJ, 311:293-5.

Kruse W, Weber E. 1990. Dynamics of drug regimen compliance-its assessment by microprocessor-based monitoring. Eur JClin Pharmacol, 38:561-5.

Loghman-Adham M. 2003. Medication Noncompliance in patients with chronic disease: issues in dialysis and renal transplantation. Am J Manag Care, 9:155-71.

Mancia G, De Backer Guy, Dominiczak A, et al. 2007. Guidelines for the Management of Arterial Hypertension: The Task Force for the Management of Arterial Hypertension of the European Society of Hypertension (ESH) and of the European Society of Cardiology (ESC). J Hypertens, 25:1105-87.

Mason JM, Dickinson HO, Nicolson DJ, et al. 2005. The diabetogenic potential of thiazide-diuretic and beta blocker combinations in patients with hypertension. J Hypertens, 23:1779-81.

Morb Mortal Wkly Rep (MMWR). 2005. Racial/ethnic disparities in prevalence, treatment, and control of hypertension - United States 1999-2002. MMWR, 54:7-9.

Morgan SG, Yan L. 2004. Persistence with hypertension treatment among community-dwelling BC seniors. Can J Clin Pharmacol, 11:267-73.

Nedeltchev K, Arnold M, Baumgartner R, et al. 2005. Vascular risk factors in the Swiss population. J Neurol, 252:1210-6.

Nuesch R, Schroeder K, Dieterle T, et al. 2001. Relation between insufficient response to antihypertensive treatment and poor compliance with treatment: a prospective case-control study. Br Med J, 323:142-6.

Pedrinelli R, Dell'Omo G, Nuti M, et al. 2003. Heterogeneous effect of calcium antagonists on leg oedema: a comparison of amlodipine versus lercanidipine in hypertensive patients. J Hypertens, 21:1969-73.

Poncelet P, Ribstein J, Goullard L, et al. 2004. Efficacy and acceptability of lercanidipine are not age dependent in patients with essential hypertension: the AGATE study. Ann Cardiol Angeiol, 53:123-30. 
Poluzzi E, Strahinja P, Vargiu A. et al. 2005. Initial treatment of hypertension and adherence to therapy in general practice in Italy. Eur J Clin Pharmacol, 61:603-9.

Puig JG, Calvo C, Luurila O, et al. 2007. Lercanidipine, enalapril and their combination in the treatment of elderly hypertensive patients: placebo-controlled, randomized, crossover study with four ABPM. J Hum Hypertens, 21:917-24.

Pullar T, Kumar S, Feely M. 1989. Compliance in clinical trials. Ann Rheum Dis, 48:871-5.

-Robles NR, Ocon J, Gomez CF, et al. 2005. Lercanidipine in patients with chronic renal failure: the ZAFRA study. Ren Fail, 1:73-80.

Sabbatini M, Leonardi A, Testa R, et al. 2000. Effect of calcium antagonists on glomerular arterioles in spontaneously hypertensive rats. Hypertension, 35:775-9.

Sasaki T, Maruyama H, Kase Y, et al. 2005. Antianginal effects of lercanidipine on the vasopressin or metacholine induced anginal models in rats. Biol Pharm Bull, 28:811-6.

Shulman N, Cutter G, Daugherty R, et al. 1982. Correlates of attendance and compliance in the hypertension detection and follow-up program. Control Clin Trials, 3:13-27.

Simons LA, Ortiz M, Calcino G. 2008. Persistence with antihypertensive medication: Australia-wide experience 2004-6. Med J Aust, 188:224-7.

Sironi G, Montagna E, Greto L, et al. 1996. Haemodynamic effects of lercanidipine in anaesthetized open-chest dogs. Arzneimittelforschung, 46:256-61.

Takabatake T, Ohta H, Sasaki T, et al. 1993. Renal effects of manidipine hydrochloride: a new calcium antagonist in hypertensive patients. Eur J Clin Pharmacol, 19:851-6.
The ALLHAT officers and coordinators for the ALLHAT collaborative research group. Major outcomes in high-risk hypertensive patients randomized to angiotensin-converting enzyme inhibitor or calcium channel blocker vs diuretic: the antihypertensive and lipid lowering treatment to prevent heart attack trial (ALLHAT). 2002. JAMA, 288:2981-97.

Urquhart J, Vrijens B. 2005. New findings about patient adherence to prescribed drug dosing regimens: an introduction to pharmionics. Eur $J$ Hospital Pharm Sci, 11:103-6.

Verdecchia P, Reboldi G, Angeli F, et al. 2005. Angiotensin-converting enzyme inhibitors and calcium channel blockers for coronary heart disease and stroke prevention. Hypertension, 46:386-92.

Veronesi M, Cicero AF, Prandin MG, et al. 2007. A prospective evaluation of persistence on antihypertensive treatment with different antihypertensive drugs in clinical practice. Vasc Health Risk Manag, 3:999-1005.

Voyaki SM, Staessen JA, Thijs L, et al. 2001. Follow-up of renal function in treated and untreated older patients with isolated systolic hypertension. J Hypertens, 19:511-9.

Vrijens B, Vincze G, Kristano P, et al. 2008. Adherence to prescribed antihypertensive drug treatments: longitudinal study of electronically compiled dosing histories. $B M J, 336: 1114-7$.

Waeber B, Burnier M, Brunner HR. 1999. Compliance with antihypertensive treatment. Clin Exp Hypertens, 21:973-85.

Weir MR, Moser M. 2000. Diuretics and beta-blockers: is there a risk for dyslipidemia? Am Heart J, 139:174-83.

World Health Organization: Adherence to long-term therapies. Evidence for action. 2003. Geneva: World Health Organization. URL: http://www.who. int/chronic_conditions/adherencereport/en/index.html. 